\title{
Investigation of the Effects of Physical Activity Levels on Sport Behavior (Fair-Play) of the Students Participating in School Sports at Different Branches (Sivas City Example)
}

\author{
Rahmi YILDIZ ${ }^{1}$, Fatih ÖZGÜL ${ }^{2, *}$ \\ ${ }^{1}$ Ministiry of Education, Sivas, Turkey. \\ ${ }^{2}$ Department of Physical Education and Sports, Cumhuriyet University, Sivas, Turkey.
}

*Corresponding Author: Fatih Özgül, Department of Physical Education and Sports, Sivas, Turkey

\begin{abstract}
The aim of this research is to examine the effects of physical activity levels on the development of sporting and fairplay characteristics of students participating in school competitions in different sports branches. In the study, 135 students who participated in school sports from 4 branches (Basketball, Football, Volleyball, Badminton) from the schools determined according to the appropriate method in Sivas city center (4 different secondary schools) and the Multidimension Behavior Scale in Sport adapted to Turkish by Balçıkanlı (2010) were applied. The Cronbach Alpha value of the scale is .88 and the scale consists of 20 items. In addition to this, the Children's Physical Activity Scale (CPAS) was adapted to Turkish by Tanir (2003) was applied to the students. The Cronbach Alpha value of the scale is .76 and the scale consists of 9 questions. SPSS (22 ver.) Package program was used for the analysis of the obtained data. Since the parametric test assumptions were fulfilled (Shapiro-Wilk); T test, Variance Analysis, Tukey test were used for the difference between the two means in the independent groups and the significant level was taken as .05. When the physical activity and behavior scores in sport of the male and female students in the study were compared, the difference was significant $(p<0.05)$. Differences were found to be significant when comparing schools in terms of Physical Activity Scale $(p<0.05)$. When the schools were compared according to the Behavior Scale in Sport, the difference was not significant $(p>0.05)$. When the physical activity and behavior scores of the students were compared according to the selected branches, the difference was found significant $(p<0.05)$. Today, the rapid advancement of technology facilitates our everyday life from one side, while the other is lazing individuals. Children and young people are most affected by immobility. It should not be forgotten that simple activities such as our children choosing bicycles instead of motor vehicles, using stairs instead of elevators, will benefit from opportunities for physical activity. As a result from this study, Physical activity scores are higher in male students than female students, while fair play scores are higher in female students than male students.
\end{abstract}

Keywords: Behavior in Sport; Fairplay; Physical Activity; Student

\section{INTRODUCTION}

Health problems and psychological problems caused by inactive life throughout the world increase the importance of physical activity day by day.Regular physical activity is important not only in terms of mental health, but also in the development and protection of all health parameters. Human body is programmed to act.According to $\ddot{O} z e r$ (2016), physical activity is a body movement that results in energy consumption and is made by skeletal muscle.Students participating in physical activities within school sports are experiencing great sociological improvements.

Children watching television at home, spending more time with computer games, and miserable nutrition as well as socially underprivileged children are transformed into lonely and unhappy individuals in the future. By means of sport and physical activity, students who produce and spend more energy without breaking away from the social environment are therefore more likely to move more and better adapt to the rules of social society in their future lives (Özer, 2016).

Today, rapid growth in urbanization and industrialization, which is a reflection of technological developments, causes changes in people's lifestyles. As a result of these changes, people became less active in every day and their physical activities decreased (Zorba, 2006). In addition, health problems 
and psychological problems are more common in people.Sport is not only a body event, it is also a moral and an aesthetic event. It is a life event for the sport as a whole and only takes place in the whole of our life when it is perceived as such. The attitude on the sport is always to be better, more beautiful and more positive. Confronting others is not a rule, but an attitude in self-knowledge, selfovercoming and self-superiority (Erdemli, 2008).

The beginning of the development line of the sport's multi-faceted behavior (fair play) can be attributed to the expression "Fair Play" which is used for gentlemanly behaviors in the English tournament rules in the second half of the 15th century. Firstly, with fairly general use, the concept of fair play in William Shakespeare in the late 16th century, in the sense of "maintaining equal opportunity" and "showing the way of chivalric thinking", entered the sports language in the 18th century (Ylldıran, 2002).Fair play does not only refer to the observable rules of the game, but also to the spirit in the game (Sezen, 2003).

Contrary behaviours to fair play in many sporting events, it affects the children in school age in the negatively, and such behavior is thought to exist in school competitions, as well. These future students, who will be important sportsmen, need to be aware of physical activity behaviors and fair play issues. Non-ethical behaviors in sports encounters have reached remarkable dimensions. But taken precautions are inadequate. Violence and non-physical situations in sports encounters seriously affect students in school age. In order to win, the students who attend the inter-school competition, can leave the fair play behavior to an end and lead to the illegal behavior.It is a very important issue that future generations should consider moral principles when doing sports. The work to be done in this regard is of great importance in preparing future athletes.

The studies about fair play have been increasing in recent years and generally thought that the inadequacy of the studies made is striking. The studies in this area are important for the students to be more sensitive about fair play (Topan, 2011).

The aim of this research is to examine the effects of physical activity levels on the development of sports and fairplay characteristics of students participating in school competitions in different sports branches. It is thought that this study will contribute to the understanding of positive and negative behavioral tendencies in school and sports areas and to make evaluations in this direction for children participating in school sports.

\section{MATERIALS AND METHODS}

Appropriate sampling method was used in this study. The appropriate sampling method is defined as choosing the sample from easily accessible and practicable units due to the limitations in terms of time, money, work power (Kincal, 2014).

\subsection{Data Collection and Data Collection Tools}

135 students who participated in school sports from four different branches (Basketball, Football, Volleyball, Badminton) selected from the center of Sivas city according to the appropriate sampling method. The Multidimensional Sports' Behavior Scale (SDSD) adapted to Turkish by Balçıkanlı (2010) and the Turkish Physical Activity Scale (CFA), adapted to Turkish by Tanir (2003), were administered by face-to-face interview technique.

\subsection{Multidimensional Sports Behavior Scale}

The 5-point likert type multidimensional sports behavior scale adapted by Balçıkanlı (2010) to Turkish is calculated between 1 and 5 points and at least 20 points and 100 points at most.

\subsection{Physical Activity Scale for Children}

The scale used in the research consists of 9 questions graded between 1-5. In the calculation of the physical activity scores, the averages of the responses given to the questions of the participants in the study were taken. The Physical Activity Scale for Children shows 5 points with the highest level of physical activity and 1 point with the lowest level of physical activity (Tanir, 2013). 
Investigation of the Effects of Physical Activity Levels on Sport Behavior (Fair-Play) of the Students Participating in School Sports at Different Branches (Sivas City Example)

\subsection{Analysis of Data}

SPSS (22.00ver.) Package program was used for the analysis of the obtained data. Since the parametric test assumptions are fulfilled (Shapiro-Wilk); Independent Samples T Test, Anova and Tukey Test were used for analyzing the data and the significance level was taken as 0.05 .The findings showed as minimum, maximum value, mean and the standard deviation in the tables.

\section{RESUltS}

In this section, the data obtained from the research are presented in tables.

Table 1. Distribution of students according to school, gender and class variables

\begin{tabular}{|c|c|c|c|c|c|}
\hline \multicolumn{6}{|c|}{ CLASSES } \\
\hline School Type & Gender & $\begin{array}{l}5 \\
n\end{array}$ & $\begin{array}{l}6 \\
n\end{array}$ & $\begin{array}{l}7 \\
n\end{array}$ & $\begin{array}{l}8 \\
n\end{array}$ \\
\hline \multirow{2}{*}{$\begin{array}{l}\text { Lütfü Tuncel } \\
\text { Secondary School }\end{array}$} & Female & 6 & 4 & 9 & 6 \\
\hline & Male & 2 & 4 & 11 & 1 \\
\hline \multirow{2}{*}{$\begin{array}{l}\text { Selçuk } \\
\text { Secondary School }\end{array}$} & Female & 1 & 3 & 11 & 4 \\
\hline & Male & 2 & 7 & 17 & 0 \\
\hline \multirow{2}{*}{$\begin{array}{l}\text { Gazi Paşa } \\
\text { Secondary School }\end{array}$} & Female & 11 & 3 & 3 & 11 \\
\hline & Male & 0 & 1 & 4 & 14 \\
\hline Total & 135 & 22 & 22 & 55 & 36 \\
\hline
\end{tabular}

From the students taken to study; 43 students from Lütfi Tuncel Secondary School constitute 31.9\% of the study (15 females, 8 males). Eight of the students are in the 5th grade, 8 of them are the 6th grade, 20 of them are the 7th grade and 7 of them are the 8th grade. In Selçuk Secondary School, 45 students (21 females, 24 males) constitute $33.3 \%$ of the study. Three of them are 5th grade, 10 of them are 6th grade, 28 of them are 7th grade and 4 of them are 8th grade.In Gazi Paşa Secondary School, 47 students (29 females, 18 males) constitute $34.8 \%$ of the study. 11 of them are 5th grade, 4 of them are 6th grade, 7 of them are 7th grade and 28 of them are 8th grade.

Table 2. Comparison of Physical Activity Levels and Fair play Total Scores

\begin{tabular}{|c|c|c|c|c|c|c|c|}
\hline & Secondary Schools & $\mathbf{N}$ & Mean & S.Dev. & Min. & Max. & Results \\
\hline \multirow{3}{*}{$\begin{array}{l}\text { Physical } \\
\text { Activity }\end{array}$} & Lütfü Tuncel & 43 & 72,93 & 13,01 & 95,00 & 95,00 & \multirow{3}{*}{$\begin{array}{l}F=4.58 \\
p=0.012\end{array}$} \\
\hline & Selçuk & 45 & 76,17 & 15,20 & 95,00 & 110,00 & \\
\hline & GaziPaşa & 47 & 67,55 & 13,08 & 110,00 & 100,00 & \\
\hline \multirow{3}{*}{ Fair Play } & Lütfü Tuncel & 43 & 82,11 & 13,84 & 110,00 & 100,00 & \multirow{3}{*}{$\begin{array}{l}F=1.87 \\
p=0.157\end{array}$} \\
\hline & \begin{tabular}{|l|} 
Selçuk \\
\end{tabular} & 45 & 84,88 & 13,45 & 100,00 & 100,00 & \\
\hline & GaziPaşa & 47 & 87,21 & 9,89 & 100,00 & 100,00 & \\
\hline
\end{tabular}

*p<0.05 important

Table 2 gives the results of physical activity levels and fair play total scores of the three schools participating in the study. According to this; the difference in physical activity scale was found to be significant when compared to schools $(\mathrm{p}<0.05)$. When the scale scores of schools are compared with each other, the difference between Selçuk Secondary School and Gazi Paşa Secondary School is found significant $(p<0.05)$. The difference between the other schools is not significant $(p>0.05)$. When compared to each other in terms of fair play, the difference is not significant $(p>0.05)$.

Table 3. Comparison of the Physical Activitiy and Fair Play Total Points According to Gender.

\begin{tabular}{|l|l|l|l|l|l|}
\hline & Gender & N & Mean & S. Dev. & Results \\
\hline \multirow{2}{*}{ Physical Activity } & Female & 64 & 67,59 & 12,94 & $\mathrm{t}=3.70$ \\
& Male & 71 & 76,23 & 14,06 & $\mathrm{p}=0.001$ \\
\hline \multirow{2}{*}{ Fair Play } & Female & 64 & 88,10 & 9,93 & $\mathrm{t}=2.97$ \\
& Male & 71 & 81,84 & 13,92 & $\mathrm{p}=0.003$ \\
\hline
\end{tabular}

*p<0.05 important

According to Table 3; the difference in physical activity and fair play scores compared to gender was found significant $(\mathrm{p}<0.05)$. Physical activity scores are higher in men, while fair play scores are higher in female students. 
Investigation of the Effects of Physical Activity Levels on Sport Behavior (Fair-Play) of the Students Participating in School Sports at Different Branches (Sivas City Example)

Table 4. Comparison of the Physical Activitiy and Fair Play Total Points According to the Class Grades.

\begin{tabular}{|c|c|c|c|c|c|c|c|}
\hline & Classes & $\mathbf{N}$ & Mean & Std.Dev. & Min & $\operatorname{Max}$ & Result \\
\hline \multirow{4}{*}{$\begin{array}{l}\text { Physical } \\
\text { Activity }\end{array}$} & 5 & 21 & 66,33 & 9,86 & 42,00 & 81,00 & \multirow{4}{*}{$\begin{array}{l}F=2.90 \\
p=0.052\end{array}$} \\
\hline & 6 & 23 & 75,91 & 12,68 & 57,00 & 95,00 & \\
\hline & 7 & 55 & 74,65 & 14,67 & 50,00 & 110,00 & \\
\hline & 8 & 36 & 69,27 & 15,23 & 34,00 & 100,00 & \\
\hline \multirow{4}{*}{ Fair Play } & 5 & 21 & 86,52 & 15,29 & 30,00 & 100,00 & \multirow{4}{*}{$\begin{array}{l}F=1.22 \\
p=0.305\end{array}$} \\
\hline & 6 & 23 & 80,34 & 12,06 & 54,00 & 99,00 & \\
\hline & 7 & 55 & 85,36 & 12,03 & 52,00 & 100,00 & \\
\hline & 8 & 36 & 85,83 & 11,74 & 58,00 & 100,00 & \\
\hline
\end{tabular}

When the physical activity scores and the fair play scores are compared according to the classes in Table 4; the difference is not found statistically significant ( $\mathrm{p}>0.05)$.

Table 5. Comparison of the Physical Activitiy and Fair Play Total Points According to Educational Situation of Families

\begin{tabular}{|c|c|c|c|c|c|c|c|}
\hline & Family Edu.Situation & $\mathbf{N}$ & Mean & S.Dev. & Min. & Max. & Result \\
\hline \multirow{4}{*}{ Physical Activity } & Primary School & 44 & 70,25 & 14,05 & 42,00 & 110,00 & \multirow{4}{*}{$\begin{array}{l}F=1.50 \\
p=0.373\end{array}$} \\
\hline & Middle School & 38 & 74,86 & 13,68 & 50,00 & 101,00 & \\
\hline & High School & 26 & 73,65 & 15,17 & 34,00 & 100,00 & \\
\hline & University & 27 & 69,92 & 14,00 & 50,00 & 99,00 & \\
\hline \multirow{4}{*}{ Fair Play } & Primary School & 44 & 86,27 & 11,98 & 62,00 & 100,00 & \multirow{4}{*}{$\begin{array}{l}F=0.80 \\
p=0.496\end{array}$} \\
\hline & Middle School & 38 & 83,34 & 11,37 & 52,00 & 100,00 & \\
\hline & High School & 26 & 86,65 & 10,96 & 57,00 & 100,00 & \\
\hline & University & 27 & 82,74 & 16,12 & 30,00 & 100,00 & \\
\hline
\end{tabular}

In Table 5, when comparing physical activity scores and fair play scores according to education statusof families, the differences are not found significant $(\mathrm{p}>0.05)$.

Table 6. Comparison of the Physical Activitiy and Fair Play Total Points According to Sports Branches

\begin{tabular}{|c|c|c|c|c|c|c|c|}
\hline & Branches & $\mathbf{N}$ & Mean & S.Dev. & Min & Max & Result \\
\hline \multirow{4}{*}{$\begin{array}{l}\text { Physical } \\
\text { Activity }\end{array}$} & Football & 46 & 74,56 & 13,41 & 42,00 & 95,00 & \multirow{4}{*}{$\begin{array}{l}F=7.47 \\
p=0.001\end{array}$} \\
\hline & Volleyball & 30 & 62,56 & 10,36 & 34,00 & 81,00 & \\
\hline & Basketball & 54 & 74,33 & 13,90 & 48,00 & 101,00 & \\
\hline & Badminton & 5 & 83,60 & 19,48 & 59,00 & 110,00 & \\
\hline \multirow{4}{*}{ Fair Play } & Football & 46 & 79,41 & 13,44 & 30,00 & 100,00 & \multirow{4}{*}{$\begin{array}{l}F=5.57 \\
p=0.001\end{array}$} \\
\hline & Volleyball & 30 & 88,50 & 7,91 & 68,00 & 100,00 & \\
\hline & Basketball & 54 & 86,44 & 12,66 & 52,00 & 100,00 & \\
\hline & Badminton & 5 & 94,80 & 8,28 & 81,00 & 100,00 & \\
\hline
\end{tabular}

\section{$* p<0.05$ important}

According to Table 6; When the physical activity scores were compared, the difference was significant $(\mathrm{p}<0.05)$. When the scale scores were compared with each other, the difference between football and volleyball, volleyball and basketball, volleyball and badminton was found significant ( $p$ $<0.05)$, while the difference between the other branches was not found significant $(\mathrm{p}>0.05)$.

In Table 6; Difference was found to be significant when the fair play scores were compared according to the branches selected by the students $(\mathrm{p}<0.05)$. The difference between football and volleyball, football and basketball, football and badminton were significant in relation to fair play scores, while the difference between the other branches was not found significant ( $p>0.05)$.

\section{DISCUSSION}

In this study, the physical activity levels of the middle school students participating in school events in different branches and the fair play were evaluated in terms of different variables. When the general scores of the students are taken into consideration, participation in physical activity is high. Moreover, 
when the fair-play behavior scores are examined, it is seen that these behaviors define the students as "highly define me" as the general average. In parallel with this study, Sezen (2009) studied the relationship between the behavior of professional footballers towards fair play and the level of empathic tendencies; soccer players stated that the behaviors in the sub-dimension of compliance with the social norms defined themselves "quite".

In the study, difference was found to be significant when comparing physical activity and fair play scores in terms of gender. Physical activity scores are higher in men than women, while fair play scores are higher in female students than male students. This is because the average of physical activity points is higher in men and fair-play points are higher in female students. Kotan (2004) investigated the fair play mentality of professional soccer team supporters and reported that fair play mentality of women is higher than that of men. In the study of Gümüş and his colleagues named "Fair Play Concept in High School Students" (2006), it was found that women compared to genders exhibited more fair play behaviors than men. In parallel, Topan (2011) stated that female students' fair play mentality is higher than male students in the study titled "Examining fair play mentality according to club experiences of students participating in inter-school football competitions in secondary education institutions". Another study, which differs from this study, found that female students were significantly higher in physical activity scores than boys in the 14-18 age group study on the evaluation of physical activity and fitness levels of male and female students (Uçar, 2014;tra.Yaprak, MT Amman, 2009), has found that male students are more likely to be tougher than female students in terms of "fair play". When the physical activity score and the fair play score were compared according to the grade levels in the study; the difference is not seen significant. However, studies conducted by Toriola and Monyeki (2012) and So (2013) have indicated that men have higher levels of physical activity than women and exhibit fewer sedentary behaviors at class level. When the physical activity scores and the fair play scores were compared according to educational status in the study, the difference is not seen significant. However, in Kotan (2004)'s study, it has been found that as the level of education increases in comparing the levels of education with fair play, the fair play levels also increase. When the physical activity and fair play behaviors were compared according to the branches in the study, significant differences appeared. Correspondingly, Koç and Güllü (2016) reported that the students who were interested in team sports, who had less physical contact with their high school students, had higher fair play and less aggressive behaviors than the students who were interested in other sport types. Similarly, another study reveals that behaviors contrary to fair play in close-contact team sports are seen more often than in individual sports (Balçıkanl, 2016). Again, in parallel with this study, Esentürk and colleagues (2015) studied on high school students showed that sportsmen values of volleyball are more meaningful than students who are interested in soccer. In contrast to these studies, there were no differences in the opinions of the athletes about the fair play, according to the study of Şebin and colleagues (2007) on university students.

\section{Conclusions}

Throughout childhood and youth, the participation rates of students in physical activity and the aspects of fair play are constantly changing. The selected branches of the students reveal differences in the levels of physical activity and fair play behaviors. It has seen that this difference is more in contact sports, which requires fighting. In branches such as football and basketball, the fair play behavior is slightly decreased due to the rival fighting, while it is thought that more fair play behaviors have emerged in sports where there are fewer contacts such as volleyball and badminton. On the other hand, although there are studies to increase participation rates in physical activities; as opposed to fair-play, acting with "prioritized understanding of winning For these reasons, while trying to make sure that our children who participate in school sports and club competitions have increased physical activity levels, we should also try to increase fair play behavior from the other side.

Today, the rapid advancement of technology facilitates our everyday life from one side, while the other is lazing individuals. Technological devices such as computer games, game consoles, mobile phones, television sets the individual to an immobile lifestyle. Children and young people are most affected by immobility. There are duties to parents and teachers to explain the negativities of this passive living situation to our children. It should not be forgotten that simple activities such as our children choosing bicycles instead of motor vehicles, using stairs instead of elevators, will benefit 
Investigation of the Effects of Physical Activity Levels on Sport Behavior (Fair-Play) of the Students Participating in School Sports at Different Branches (Sivas City Example)

from opportunities for physical activity. With physical activity and participation in sport, our children will learn positive behaviors such as gentility, virtue, friendliness, competition, sharing and accepting to lose, and these activities will facilitate convenience in everyday life.

As a result from this study, Physical activity scores are higher in male students than female students, while fair play scores are higher in female students than male students.

\section{SUGGESTIONS}

- It is believed that further work on physical activity and fair play on more schools and students will contribute to enlightenment of this issue.

- In order to increase participation rates in physical activity, these activities should be supported by the Ministry of National Education.

- Physical education teachers should give more place to constructive activities in order to gain students fair play understanding and should set an example for students with their own behaviors.

\section{ACKNOWLEDGEMENTS}

This paper presented as an oral presentation on 21st April 2017 at the International Sport, Tourism and Recreation Student Congress held in Burdur. The study has an Ethic Comitee Report taken from Cumhuriyet UniversitySocial and Human Sciences Ethic Commission on July 2017.

\section{REFERENCES}

[1] Balçıkanlı, Gülfem Sezen.(2017). "Ethical Purpose of Contest Sports." Sport and Performance Research magazine 8(1):47-51.

[2] Erdemli, A.(2008). Human Who Does Sports, İstanbul: E Publications.

[3] Esentürk, O.K., İlhan, E.L, Çelik, O.B. (2015). Examination Of High School Students' Sportsman like Conducts In Physical Education Lessons According To Some Variability. Science, Movement And Health, 15(2): 627-634.

[4] Gümüş, H.,Saraçlı, S,, Karakullukçu, Ö. F., Doğanay, G.,Kurtipek, S. (2016). Fair play concept in secondary school students. International Journal Of Science Culture And Sport, 4(2):2148-1148.

[5] Kıncal, Remzi. (2015). Scientific Research Methods. Ankara: Nobel Academic Publishing.

[6] Koç, Y., \& Güllü, M. (2017). Research Into Sportspersonship Behavior of High School Students in Physical Education Course in Terms of Some Variables. SPORMETRE, 15(1):19-30.

[7] Koç, Y. (2017). Relationships between the Physical Education Course Sportsmanship Behaviors with Tendency to Violence and Empathetic Ability (Note 1). Journal of Education and Learning; 6(3):169-180.

[8] Kotan, R. (2004). A Research On the Fair Play Understandings of Professional Football Team Fans (Trabzon Example). Unpublished Master Thesis. Ankara Gazi University, Institute of Educational Sciences; 67.

[9] Özer, M.K. (2016). Physical Fitness. Ankara: Nobel Academic Publishing.

[10] Sezen, G., Yıldıran, G. (2003). Fair Play Understandings of Professional and Amateur Footballers. Social Sciences Congress in Physical Education and Sport (10 11) October) Notifications Book. (Ed:G.Y1ldıran, P. Doğan, E. Esra Erturan), Ankara: Sim publishing, 13-20.

[11] Sezen, B.G. (2009). The Relationship Between the Behavior of Professional Footballers towards Fair Play and the Level of Empathic Tendency. Unpublished Phd Thesis. Ankara Gazi University, Institute of Health Sciences.

[12] So, W. (2013). Physical Activity And Sedentary Behavior's Association With Body Weight in Korean Adolescents. International Journal Of Sport Nutrition And Exercise Metabolism,23(1):1-10.

[13] Şebin, K., Tozoğlu, E., Yılmaz, S., Demirel, N., Bostancı, Ö. (2007). The Opinions About Fair Play Of University Students Who Doing Sport. Journal of Physical Education and Sport Sciences, 9(2).

[14] Topan, A. (2011). Examination of Fair Play Perceptions of Students Attending School Football Competitions in Secondary School Institutions According to Club Experiences. Unpublished Master Thesis. Ankara Gazi University, Institute of Educational Sciences.

[15] Toriola, O., Monyeki, M. (2012). Health-Related Fitness, Body Composition And Physical Activity Status Among Adolescent Learners: The Pahl Study. African Journal For Physical, Health Education, Recreation And Dance. 18,4(1): 795-811. 
Investigation of the Effects of Physical Activity Levels on Sport Behavior (Fair-Play) of the Students Participating in School Sports at Different Branches (Sivas City Example)

[16] Uçar, M. (2014). Assessment of Physical Activity and Compliance Levels of Female and Male Students in the 14-18 Age Group of Konya Provincial Orphanage Dormitories;Yaprak, MT Amman - Turkey Kick Boxing Federation Sports Science Magazine.

[17] Y1ldiran, İ. (2002). Fair Play Content, Appearance and Development Perspectives in Turkey. 7. International Sports Science Congress; 27-29 October, Kemer / Antalya.

[18] Zorba, E. (2006). Physical Fitness. Ankara: Gazi Publishing.

Citation: Rahmi YILDIZ1, Fatih ÖZGÜL. " Investigation of the Effects of Physical Activity Levels on Sport Behavior (Fair-Play) of the Students Participating in School Sports at Different Branches (Sivas City Example)." International Journal of Sports and Physical Education (IJSPE), vol 3, no. 4, 2017, pp. 40-46. doi:http://dx.doi.org/10.20431/2454-6380.0304007.

Copyright: (C) 2017 Authors. This is an open-access article distributed under the terms of the Creative Commons Attribution License, which permits unrestricted use, distribution, and reproduction in any medium, provided the original author and source are credited. 